\title{
La orientación autonomista de la política exterior argentina (2003-2015)
}

Carla Morasso*

\begin{abstract}
Resumen
El propósito del presente artículo es caracterizar la política exterior desarrollada durante las administraciones de Néstor Kirchner (2003-2007) y Cristina Fernández de Kirchner (2007-2015). Para ello se presentan los factores centrales en torno a los cuales se estructuró una política exterior de orientación autonomista -implementación de un modelo de desarrollo nacional; restricción a la injerencia de actores externos en los procesos de toma de decisión; profundización de los vínculos regionales; y diversificación de las relaciones externas-, los cuales son examinados a partir de la definición de la estrategia neodesarrollista implementada y de los casos del pago de la deuda al Fondo Monetario Internacional (FMI) y al Club de Paris, los ajustes en la relación con Estados Unidos, la acentuación de la integración suramericana, y la diversificación de vínculos con los países en desarrollo.
\end{abstract}

Palabras Claves: política exterior - autonomía - Argentina

\section{The autonomist orientation of the Argentinian foreign policy} (2003-2015)

\begin{abstract}
The aim of this paper is to characterize the Argentinan foreign policy during the administrations of Néstor Kirchner (2003-2007) and Cristina Fernández de Kirchner (2007-2015). The contribution pretends to analize the main factors driving a model of foreign policy with an autonomic orientation -a national economic development model; restriction on the interference of foreign actors in decision-making processes; deepening regional relations; and diversification of external relations-. In order to do this, we examine the neodevelopmentalist strategy and the cases of the payment to the IMF and the Paris Club, the adjustments in the relations with the United States, the South American integration, and the links with the developing countries.
\end{abstract}

Key words: Foreign policy - Autonomy - Argentina

Trabajo enviado: 04/04/2016 Trabajo aceptado: 02/05/2016

\section{Introducción}

Una gran parte de los debates sobre política exterior en América Latina se refieren a la posibilidad de ejercer políticas autónomas para disminuir la dependencia económica y política externa (Vigevani y Ramanzini Júnior, 2014). En el caso argentino, a partir del retorno a la democracia, se construyó un juego de equilibrio entre las tendencias autonomistas y las dependentistas (Simonoff, 2010) que signaron las lecturas sobre los resultados alcanzados en las diferentes administraciones.

\footnotetext{
* Doctora en Relaciones Internacionales, Universidad Nacional de Rosario (UNR, Argentina). Docente e Investigadora de la Facultad de Ciencia Política y Relaciones Internacionales (UNR). Coordinadora del Programa de Estudios América Latina-África (PEALA) / Programa de Estudios de Relaciones y Cooperación Sur-Sur (UNR). Analista del Centro de Estudios Políticos Internacionales de la Fundación para la Integración Federal. Contacto: carlamorasso@yahoo.com.ar
} 
En particular, en lo que respecta a la política exterior de los gobiernos de Néstor Kirchner (2003-2007) y Cristina Fernández de Kirchner (2007-20015), han sido numerosos los trabajos que se ocupan de analizarla en clave autonómica (Bologna, 2008, 2010; Bueno, 2015; Corigliano, 2008; Lorenzini, 2012; Miranda, 2013; Simonoff, 2008, 2010, entre otros). En línea con estos aportes, el presente trabajo se propone describir los elementos que permiten caracterizar a la política exterior ${ }^{1}$ de este período como una política de "orientación autonomista", en tanto procuró disponer de mayores márgenes de maniobra internacional para llevar adelante acciones externas en función del interés nacional expresado en términos de desarrollo.

Considerando lo expuesto, en el primer apartado se ofrecen las consideraciones conceptuales esenciales para comprender el significado de la autonomía en la actualidad. Posteriormente, en el segundo apartado, se exponen los elementos centrales que permiten caracterizar el accionar internacional kirchnerista a partir de la noción de "política exterior de orientación autonomista".

En el tercer punto, en tanto, se da cuenta del modelo neodesarrollista que subyació en las decisiones de política externa. Luego se presentan sintéticamente cuatro temas claves que se consideran representativos de cada una de las dimensiones que componen la política exterior de orientación autonomista. De este modo, en el cuarto apartado se expone la salida del default y la cancelación de las deudas con el Fondo Monetario Internacional (FMI) y el Club de Paris; en el apartado cinco se aborda el replanteo del vínculo con Estados Unidos; el sexto apartado se encarga de la promoción de la integración suramericana; y en el último apartado se trata la cooperación Sur-Sur, tomando como caso testigo los vínculos con África Subsahariana.

\section{Nuevas lecturas sobre la autonomía en el siglo XXI}

Las Relaciones Internacionales fueron concebidas como una disciplina eurocéntrica, nacida en Estados Unidos en el siglo XX a los efectos de dar respuestas a los desafíos que el mundo planteaba para los países desarrollados. Desde entonces ha primado la producción de teorías centradas en las problemáticas de inserción internacional de los países del Norte. De allí se desprende el valor de los aportes latinoamericanos, que desde una perspectiva propia propone conceptos generados en función de las realidades del Sur.

El denominado "pensamiento latinoamericano" en relaciones internacionales ha generado una explicación sobre la división del sistema internacional entre un centro y una periferia que no fue comprendida como una condición de resignación ante la falta de poder, sino que dio lugar a que se entendiera que "la periferia tenía alternativas, no sólo para cambiar las percepciones que se manejan en torno a ella, sino también para proponer otro tipo de relaciones con el mundo" (Miranda, 2005:50).

A partir de allí se han formulado diferentes herramientas conceptuales para comprender y explicar el comportamiento de los países de la región, entre las que se destaca el concepto de autonomía. En Argentina, los trabajos conceptuales en torno a la autonomía comenzaron a tener peso a partir de los aportes de Juan Carlos Puig, hace más de tres décadas, y se extienden hasta nuestros días a través de trabajos como los de Escudé (1995) sobre "realismo periférico"; Russell y Tokatlián $(2001 ; 2002 ; 2013)$ sobre "autonomía relacional" y autonomía como "gran estrategia"; Colacrai (2009) sobre la "autonomía regional"; y Briceño Ruiz y Simonoff (2014) sobre la relectura de la autonomía en el siglo XXI, lo cual da la pauta, tal como señala Romero (2009), de que la "teoría de la autonomía" se ha convertido en una categoría central para analizar la política exterior, y que su andamiaje conceptual es aún en la actualidad una herramienta analítica valiosa.

\footnotetext{
${ }^{1}$ Se entiende por "política exterior" toda política pública de carácter interméstico que expresa los objetivos de un Estado y los intereses de sus múltiples actores públicos y privados en su vinculación con el sistema internacional. Es producto de un proceso político que involucra a diferentes actores que conforman el gobierno en función de su posición burocrática, la distribución de poder en la estructura gubernamental, las vinculaciones con la sociedad civil y el programa de gobierno (Morasso, 2015).
} 
En efecto, los enfoques de la autonomía han sido revisitados, repensados y enriquecidos por los académicos argentinos y brasileños en la última década como lentes para entender el fenómeno de la inserción internacional de estos países, lo cual no ha sucedido con las teorías del desarrollo y la dependencia (Lorenzini y Pereyra Doval, 2013).

El concepto de autonomía comenzó a ser discutido en el contexto de la Guerra Fría para disminuir vulnerabilidades y aumentar los márgenes de maniobra ante las potencias hegemónicas de cada bloque. Posteriormente, en los noventa, las estrategias autonómicas dejaron de ser relevantes frente a la caída del Muro de Berlín y la expansión de la globalización neoliberal. En América Latina, la crisis de la deuda, los desequilibrios fiscales, la falta de financiamiento internacional y la caída de los precios de las materias primas configuraron el escenario en el cual comenzó el período de "crisis del autonomismo"2.

En los inicios del nuevo milenio, la discusión en términos teóricos y políticos en torno a la autonomía se reabrió en un contexto internacional y regional propicio a tal fin. A nivel global, tuvo lugar un proceso de transformación signado por el cambio ante la emergencia de nuevas potencias, en particular en las dimensiones económica y política, que desafiaron a Estados Unidos y desestabilizaron la balanza de poder mundial (Zakaria, 2008). A nivel regional, en tanto, en los gobiernos latinoamericanos se recuperó el valor de la coordinación política de las estrategias autonómicas (Colacrai, 2009).

A pesar del paso del tiempo, las estrategias autonómicas conservaron sus elementos constitutivos históricos:

"el imperativo del desarrollo económico; la búsqueda de la paz; la extensión del alcance geográfico de las relaciones exteriores; la restricción del poder de las grandes potencias, particularmente de Estados Unidos; así como la construcción de un orden internacional más equitativo. Sus medios son: el regionalismo; la apelación al derecho; el recurso a los organismos internacionales, y el empleo de modalidades de soft power" (Russell y Tokatlián, 2013:161).

Es decir, la idea de autonomía conservó la esencia original del concepto expresado por Puig (1984) en el sentido de que es la máxima capacidad de decisión propia que puede lograr un Estado considerando los condicionamientos objetivos del mundo real. En ese sentido, se destaca que actualmente la autonomía implica "que el Estado nación cuente con un modelo de desarrollo económico propio; con un sistema político inclusivo y de mayorías; y, que participe en el sistema internacional en función de sus propios intereses" (Pereyra Doval, 2014:55).

Asimismo, contemporáneamente se subrayan nuevos aspectos vinculados a la interdependencia y a la globalización, imperantes en el sistema internacional. De acuerdo con Russell y Tokatlián (2002), actualmente la autonomía no puede ser abordada desde el aislamiento, la autosuficiencia y la oposición, sino a través de las estrategias de internacionalización y regionalización. De este modo, la cooperación con otros actores y la participación activa en organizaciones y regímenes internacionales, son fundamentales para que un país desarrolle capacidades autonómicas.

En este sentido cabe señalar el término acuñado por Vigevani y Cepaluni (2007) de "autonomía por la diversificación" para caracterizar los gobiernos de Da Silva en Brasil, como la adhesión del país a los principios y normas internacionales a través de alianzas Sur-Sur y acuerdos con socios no tradicionales, dado que se considera que ellos reducen las asimetrías en las relaciones con los Estados más poderosos e incrementan la capacidad negociadora internacional.

Por tanto, la autonomía está relacionada con la capacidad de los Estados de tomar decisiones funcionales a sus intereses e independiente de los poderes globales y de mantener

\footnotetext{
${ }^{2}$ En el caso argentino, de acuerdo con Bologna (2008), la política exterior menemista respondió al modelo de "dependencia nacional" en términos de Puig, siendo muy difícil encontrar discrepancias entre el interés estratégico argentino y los intereses estadounidenses.
} 
vínculos con todos los países del mundo, considerando siempre las restricciones provenientes del sistema internacional (Gomes Saraiva, 2011; Gratius y Gomes Saraiva, 2013).

En lo que respecta a la práctica autonomista en Argentina, a lo largo de la historia, diferentes gobiernos adoptaron estrategias autonomistas ${ }^{3}$ que, a nuestro entender, se estructuraron principalmente alrededor de cuatro factores: el impulso de un modelo de desarrollo nacional, la profundización de los vínculos regionales, la restricción del poder de las grandes potencias y la diversificación de las relaciones externas. Los mismos fueron retomados durante las administraciones kirchneristas, tal como se observará en los siguientes apartados ${ }^{4}$.

\section{La orientación autonómica de la política exterior kirchnerista}

La profunda crisis social, económica y política de $2001^{5}$ evidenció los límites del modelo de inserción neoliberal en Argentina y la necesidad de una nueva orientación de la política exterior más autónoma que respondiera a los intereses domésticos antes que a los externos. No obstante, los ejercicios para implementar un nuevo esquema de política exterior se vieron retrasados tanto por la situación de colapso económico y social argentino, que demandaba toda la atención del gobierno, como por el escaso margen de gobernabilidad con el cual asumió Néstor Kirchner su mandato en mayo de $2003^{6}$, lo cual requería a nivel doméstico reforzar la imagen presidencial de gobernabilidad.

Sin embargo, la génesis del mismo se puso de manifiesto desde el momento en que el Presidente pronunció su discurso de asunción, donde señaló que desde el proyecto nacional el país se integraría al mundo "dando pasos concretos hacia consensos políticos basados en el fortalecimiento del derecho internacional, el respeto a nuestras convicciones, la historia y las prioridades nacionales", que siendo "(...) partidarios en la política mundial de la multilateralidad como somos, no debe esperarse de nosotros alineamientos automáticos sino relaciones serias, maduras y racionales que respeten las dignidades que los países tienen" y que "la prioridad en política exterior será la construcción de una América Latina políticamente estable, próspera y unida con base en los ideales de democracia y justicia social". Asimismo, remarcó el inclaudicable reclamo de soberanía sobre las Islas Malvinas y la necesidad de estrechar vínculos con otras naciones en desarrollo (Kirchner, 2003).

\footnotetext{
${ }^{3}$ Durante las Presidencias Juan Domingo Perón (1946-1955 y 1973-1976), Arturo Frondizi (1958-1962) y de Arturo Illia (1963-1966) y en la primera etapa del gobierno de Raúl Alfonsín, que se extendió entre su asunción y el "giro realista", signado por el acercamiento a Estados Unidos y la puesta en marcha del "Plan Austral" (1983-septiembre 1984). En relación al gobierno de Alfonsín, cabe aclarar que hay autores que interpretan que durante este gobierno se continuó una política autonómica pero que reconocía que con los Estados Unidos debían existir relaciones maduras (Simonoff, 2013).

${ }^{4}$ De acuerdo a Simonoff (2010), a partir del retorno a la democracia, la política exterior argentina construyó un juego de equilibrio entre las tendencias autonomistas y las dependentistas, y las políticas externas kirchneristas respondieron a la primera, que privilegia la región y la relación con Brasil, ante la inserción restringida dependiente de la potencia hegemónica.

${ }^{5}$ Durante los noventa, la tasa de desempleo se triplicó pasando de representar 6,3\% en 1992 a $18,3 \%$ en 2001, y superando el $21 \%$ en la eclosión de la crisis económica. Si a este porcentaje se suman el correspondiente a las personas subempleadas, la proporción aumenta hasta llegar al 50\% durante la crisis. Otro dato que muestra la profundidad de la crisis es la reducción del ingreso. Entre 1992 y 1996 se registró una reducción del ingreso real de 7,1\%. A partir de 1998 los hogares perdieron un 13\% adicional de sus ingresos reales hasta 2001, a lo que se suma un 30\% más durante la crisis que marcó el fin de la convertibilidad (UNICEF, CEPAL, 2006).

${ }^{6}$ En las elecciones presidenciales del 27 de abril de 2003, el ex Presidente Carlos Menem fue el más votado en la primera vuelta, con el $24,45 \%$ de los votos, seguido por Néstor Kirchner, con el 22,24\%. El insuficiente apoyo electoral de las fórmulas Menem-Romero y Kirchner-Scioli llevó al ballotage, ya que en el sistema electoral argentino, para que un Presidente sea electo en primera vuelta debe alcanzar umbral mínimo de votos del $40 \%$ con una diferencia del $10 \%$ con la segunda lista. En caso que ambas superen el $40 \%$, la primera opción tiene que lograr el $45 \%$ de los sufragios. Las negativas expectativas de Menem lo llevaron a retirarse y renunció a presentarse en la segunda vuelta.
} 
De estas palabras se desprenden las ideas subyacentes de que la política exterior debía estar a disposición de la recuperación nacional y que el Estado tenía un rol central en el desarrollo nacional, el cual representaba el interés prioritario de la nación. El gobierno de Néstor Kirchner planteó "hacer de la Argentina un país normal", y la normalidad no tenía que ver con la inserción en el primer mundo ni con el alineamiento automático, sino con la reconstrucción de una identidad que priorizaba la pertenencia latinoamericana, el ejercicio de la autonomía y "particularmente el desarrollo de un modelo distinto a aquel en auge en los años noventa" (Pignatta, 2010:153).

En materia de política exterior, el kirchnerismo mantuvo los principios que caracterizaron históricamente el comportamiento internacional argentino democrático: promoción de la paz y la democracia, la no intervención en asuntos internos de terceros Estados, la solución pacífica de las controversias y el respeto al derecho internacional, mereciendo un lugar especial la defensa de los derechos humanos y el reclamo de soberanía sobre las Islas Malvinas y las Islas del Atlántico Sur $^{7}$. Pero por sobre todo, se procuró una visible ruptura con los ejes de la política menemista basada en el "alineamiento automático" o "relaciones carnales" con Estados Unidos".

En tal sentido, al analizar el gobierno de Néstor Kirchner, Bologna (2010:44-45) concluye que en lo que respecta a las relaciones con Estados Unidos su política exterior se ajustó al modelo puigiano de autonomía heterodoxa dado que no aceptó "la imposición dogmática de apreciaciones políticas y estratégicas que sólo consulten el interés propio de la potencia hegemónica y a su vez discrepa con ella en varias cuestiones", entre ellas, el modelo de desarrollo interno, pero que mantuvo "sintonía en las cuestiones estratégicas con la potencia dominante".

A partir de 2003 se evidenció un cambio en las prioridades geográficas de la agenda -a favor de la integración suramericana y el reposicionamiento del Sur-, la determinación de no renunciar a la autonomía en las decisiones, de participar activamente en la democratización del sistema internacional y de revalorizar el multilateralismo como mecanismo de inserción en el mundo, en contraposición al bilateralismo predominante en la década anterior.

Además, la autonomía comenzó a formar parte del discurso, como articuladora entre las demandas sociales y los lineamientos de política exterior, tal como puede observarse en pasajes presidenciales como el siguiente:

“(...) estamos cambiando la Argentina, sabe que estamos trabajando para recuperar la clase trabajadora, sabe que estamos recuperando la clase media con movilidad ascendente, que estamos reconstruyendo el empresariado nacional, la potencialidad del país, que estamos volviendo a ser un país autónomo en la globalización (...)" (Kirchner, 2007).

De este modo, existieron dos factores considerados por Romero (2009) como centrales para la generación de "prácticas autonómicas": la existencia de un grupo de poder que se identifica a sí mismo como relativamente independiente respecto del centro de poder y tiene la capacidad de trazarse objetivos propios; y la existencia de un discurso autonómico que ofrece la articulación de significado entre el proyecto nacional propuesto y su puesta en escena internacional.

Consecuentemente, es posible caracterizar la política exterior argentina implementada por los gobiernos de Néstor Kirchner y Cristina Fernández de Kirchner entre 2003 y 2012 como

\footnotetext{
${ }^{7}$ En el marco del $30^{\circ}$ aniversario de la Guerra de Malvinas, se realizó el 26 de febrero de 2012 en Tierra del Fuego una sesión especial de la Comisión Bicameral de Relaciones Exteriores del Congreso donde se firmó por unanimidad entre representantes del oficialismo y fuerzas opositoras la "Declaración de Ushuaia”, que ratifica la soberanía sobre las Islas Malvinas y respalda las medidas del Gobierno en torno a la disputa con el Reino Unido. El siguiente 21 de marzo, por unanimidad, el Congreso convirtió en Ley la Declaración.

${ }^{8}$ Durante una reunión con funcionarios del Banco Interamericano de Desarrollo en 1991, el Canciller Guido Di Tella pronunció la célebre definición sobre el tipo de relaciones que se pretendían tener con Estados Unidos: "No queremos tener relaciones platónicas: queremos tener relaciones carnales y abyectas".
} 
una "política exterior de orientación autonomista". La misma refiere a los valores, ideas y acciones externas de un gobierno que, en función del interés nacional expresado en términos de desarrollo, procura mayores márgenes de maniobra en el sistema internacional a través de la restricción de la influencia de poderes externos en la toma de decisiones y la profundización de los vínculos regionales y diversificación de los vínculos internacionales a través de la cooperación Sur-Sur.

En términos de Russell (1990), la orientación está relacionada con los principios y valores particulares sustentados por el gobierno tanto en el marco del régimen democrático como con las políticas específicas implementadas. Partiendo de dicha concepción, la orientación autonomista refiere a la lectura del mundo que realizan los gobiernos kirchneristas y las decisiones que toman para lograr mayores márgenes de autonomía en función de lo que consideran los intereses nacionales. Es decir, se comprende a la "orientación autonomista" en el sentido de decisión política que se plasma en el plano discursivo y en la direccionalidad que el gobierno imprime en las acciones".

De este modo, cuatro elementos centrales que dan cuenta de una orientación autonomista de la política exterior son posibles de observar en el período estudiado: el modelo de desarrollo interno, la restricción de la influencia de poderes externos en la toma de decisiones, la profundización de los vínculos regionales y la diversificación de las relaciones externas. Asimismo, cabe señalar que este período histórico estuvo signado por un contexto internacional que, a pesar de las variaciones, se caracterizó por el bajo perfil de la subregión suramericana en la agenda estadounidense, la emergencia de poderes medios y la asunción de gobiernos progresistas en América del Sur ${ }^{10}$.

\section{La estrategia neodesarrollista}

Las estrategias de desarrollo se encuentran entre los principales elementos domésticos determinantes para comprender las políticas exteriores de los países de América Latina. No sólo son importantes porque explican el comportamiento de las vinculaciones económicas internacionales, sino también porque permean la orientación política hacia el exterior (Van Klaveren, 1992).

En el caso de la política exterior de orientación autonomista, la estrategia de desarrollo adoptó características del modelo neodesarrollista, donde el Estado actúa como inductor del desarrollo y que posee capacidad de coordinación y regulación del mercado.

De acuerdo con Araníbar y Rodríguez (2013) las políticas neodesarrollistas promueven los equilibrios macroeconómicos, con tasas de interés bajas, tipo de cambio competitivo e inflación controlada para alentar la inversión en el sector exportador; procura generar condiciones para que las empresas nacionales puedan competir a nivel internacional; y redistribuye el ingreso para ampliar el mercado interno.

En Argentina, la estrategia neodesarrollista propició la exportación de productos primarios, en los cuales el país cuenta con ventajas comparativas internacionales, apuntando a promover el ingreso de divisas necesarias para tomar decisiones financieras internacionales

\footnotetext{
${ }^{9}$ En este sentido, aludimos principalmente al propósito que se procura con una decisión política y no al mantenimiento de sus resultados a lo largo del tiempo, tal como lo entiende Miranda (2013) al plantear que una estrategia autonomista debe sostener en el tiempo el control, mediante la movilización de recursos de poder, sobre las variables permisividad internacional, situaciones de dependencia y relaciones interdependientes. De acuerdo con el autor, los gobiernos kirchneristas movilizaron recursos que no lograron sostener un proyecto autonomista. La influencia internacional no fue importante, a pesar de que se intentaron exportar los avances y valores vinculados a la democracia y los derechos humanos, y además el crecimiento económico que se debió a una coyuntura mundial favorable no se transformó en recursos de poder para respaldar una estrategia autonomista.

${ }^{10}$ Estos factores externos no serán abordados en profundidad en el presente trabajo, si bien se reconoce su relevancia para comprender el proceso analizado
} 
autónomas y fortalecer la balanza externa. Pero además de las exportaciones del sector agrícola, se incentivó la exportación de productos con valor agregado, con el objeto de fortalecer el empleo y el crecimiento económico interno.

Cabe señalar que esta idea del crecimiento económico nacional basado en una visión desarrollista, que promueve la expansión de la infraestructura y proyectos industrialistas, está en la base de las concepciones autonomistas, tal como lo observa Gomes Saraiva (2011) para el caso brasileño, y que, además en un contexto de amplio dominio de las relaciones capitalistas y del capital transnacional, no refiere a un regreso al modelo de sustitución de importaciones. En efecto, durante los gobiernos kirchneristas, el imperativo industrialista reapareció en el marco de una economía abierta, donde se reconoció la necesidad de una orientación exportadora y el mantenimiento general de los principios básicos del libre comercio internacional, aunque con restricciones y regulaciones que tenían como propósito político-económico resguardar el mercado doméstico ${ }^{11}$. De este modo:

"Pensar el interés en términos de desarrollo económico se orientaba a recuperar la economía y aumentar el comercio exterior, ya que de ellos dependía la solución de los problemas domésticos más serios. Alcanzar este objetivo requería la diversificación de los mercados y la multiplicación de la oferta exportable" (Lorenzini, 2012: 25).

Como resultado de las acciones neodesarrollistas, el gobierno de Néstor Kirchner logró una importante recuperación económica con tasas de crecimiento elevadas ${ }^{12}$. Así, la aplicación de políticas de redistribución del ingreso, la consolidación del mercado interno y la promoción de las exportaciones, permitieron al gobierno contar con los recursos simbólicos y materiales para llevar adelante sus propuestas en política externa.

\section{La salida del default y el pago de la deuda al FMI}

El factor autonomista relativo a la restricción de la influencia de poderes externos en la toma de decisiones fue plasmado en la renegociación de la deuda y la salida del default ${ }^{13}$, junto con el pago de la deuda al FMI al mostrar un gobierno con poder de decisión para alejarse de aquellos organismos que habían dictado las normas económicas del país durante los noventa.

En el año 2005, la recuperación de la economía se cristalizó en tasas de crecimiento cercanas al $8 \%$ anual y la reactivación de la capacidad industrial ociosa, motivo por el cual se preveía que el país necesitaría de fondos frescos que el default alejaba. El país requería generar confianza para poder abrir negociaciones financieras y comerciales. De este modo, en un marco de distanciamiento del G-8 y con un gesto favorable del gobierno de los Estados Unidos, el gobierno de Néstor Kirchner impulsó la negociación de la deuda. Luego de un año de conversaciones, el Ministro de Economía, Roberto Lavagna, presentó en el mes de enero de 2005 una oferta de canje de deuda que fue aceptada por el 76\% de los acreedores. Al canje de 2005, le siguió el del año 2010, presentado en el mes de abril por el Ministro de Economía Amado Bodou.

\footnotetext{
11 Grottola (2010) señala algunas restricciones en mercados agropecuarios y en la importación de ciertos productos mediante la ampliación de la vigencia de licencias automáticas y no automáticas, en respuesta a la crisis financiera internacional. Por otra parte, a partir de 2011 se tomaron nuevas medidas de corte proteccionista en sectores relacionados con productos textiles, químicos, caucho y máquinas y equipos producidos en el país y donde la balanza comercial comenzaba a ser deficitaria. Estas políticas generaron reclamos en la Organización Mundial de Comercio (OMC) que finalizaron en fallos negativos (Ver Carugati, 2015; Jueguen, 2015).

${ }^{12}$ En 2003 el país comenzó un proceso de recuperación económica con tasas promedio de crecimiento del PBI del 8\% anual, tendencia que se revirtió a partir de 2012 siendo el crecimiento del PBI en 2014 del 0.5\% (Banco Mundial, 2016). El crecimiento económico impactó fuertemente en la dimensión social: entre 2003 y 2008 el desempleo descendió del 20\% a 7\% y la de pobreza del $43 \%$ al 10\% (Consejo Nacional de Coordinación de Políticas Sociales / PNUD, 2010).

${ }^{13}$ La cesación de pagos declarada en diciembre de 2001 afectó a bonos por 81.200 millones de dólares y a préstamos por otros 6.800 millones.
} 
Tras esta reapertura del canje, el 93\% de la deuda en default del año 2001 se encontraba canjeada por nuevos títulos con una importante quita de capital ${ }^{14}$.

Paralelamente, se comenzó a replantear la relación con el FMI, al cual el gobierno cuestionaba fuertemente por su responsabilidad en la crisis de 2001. El 13 de diciembre de 2005, el Presidente de Brasil, Luiz Inacio "Lula" da Silva, anunció que su gobierno había decidido cancelar su deuda con el FMI. Dos días después, en un acto celebrado en la Casa Rosada, el Presidente Kirchner anunciaba una decisión en el mismo sentido y el Fondo se mostró en acuerdo ${ }^{15}$.

Si bien esto no daba por saldada la cuestión de la deuda externa, la evolución hacia una virtual independencia decisional respecto del FMI le permitió al gobierno manejarse con un margen de maniobra más amplio tanto en las negociaciones con otros actores internacionales como con actores en el ámbito doméstico y tuvo un significado simbólico muy importante. Desde la década del ochenta, la deuda externa había actuado como un condicionante económico y político para la inserción argentina en el mundo. No sólo era una pesada carga para la economía del país, sino que también funcionaba como un mecanismo de sujeción política que permitió que los organismos financieros internacionales intervinieran en las políticas económicas y de desarrollo nacionales (Miguez, 2013).

La disminución de la deuda externa marcó la recuperación económica del país y la mayor independencia de los organismos financieros internacionales ${ }^{16}$. En 2002 la deuda externa equivalía al 166\% del PBI, en tanto en junio de 2012 representaba un $41 \%$ del PBI (MECON, 2012). Los servicios sobre la deuda, que representaban el $22 \%$ de los recursos tributarios y el $38 \%$ de las exportaciones en 2001 pasaron a significar el 8\% y el 9\% respectivamente en 2005 (Miguez, 2013).

Posteriormente, en mayo de 2014, el gobierno de Cristina Fernández de Kirchner abordó la cuestión de la deuda con el Club de Paris, que se vislumbraba como la clave para atraer inversiones y capitales extranjeros. Ese año, el gobierno puso en marcha un plan de estabilización económica que implicó devaluar y aumentar las tasas de interés y que implicaba dar señales al mercado financiero internacional para acceder a créditos. En este marco se insertaba la cancelación de la deuda con el Club de París, junto a la finalización de los diferendos en el

\footnotetext{
${ }^{14}$ Tras fallos de primera y segunda instancia en contra de la Argentina, el país había apelado la medida para que el caso fuera tratado por la Suprema Corte de Justicia, donde había sido rechazado en junio de 2014. Tras dicha instancia, el gobierno de Fernández de Kirchner y los fondos buitres mantuvieron durante varios meses una serie de encuentros a instancias del mediador judicial, Dan Pollack, nombrado por Griesa. En todos los casos, el Gobierno argentino planteó como oferta las condiciones de los canjes 2005 y 2010 , apelando a las restricciones que le imponía la cláusula RUFO (Rights Upon Future Offers), que impedía a la Argentina mejorar ofertas a sus acreedores respecto a las que accedieron quienes aceptaron los canjes de 2005 y 2010. Dicha cláusula venció el 31 de diciembre de 2014 para las operaciones mencionadas. El gobierno de Cristina Fernández de Kirchner finalizó en diciembre de 2015 sin haber presentado una nueva propuesta de negociación. Por otra parte, dado que el fallo de Griesa se mantuvo en el período, algunos de los pagos de vencimiento realizados por Argentina no pudieron ser cobrados por los acreedores reestructurados, lo cual para algunos implica un default selectivo. De este modo, en diciembre de 2015, cuando asumió el Presidente Mauricio Macri, el 7\% de la deuda original se encontraba aún en litigio en tribunales de Estados Unidos. Entre las primeras medidas del nuevo gobierno se destacó la negociación con los holdouts y el inicio del pago de la deuda no reestructura por 10.500 millones de dólares en el mes de abril de 2016 (Carillo, 2016).

${ }^{15}$ Otros países que cancelaron su deuda con el FMI fueron Brasil (2005), Ecuador (2007), Filipinas (2006), Rusia (2004), Uruguay (2006) y Venezuela (2007). La cancelación de la deuda con el Fondo se realizó en un solo pago de 9.810 millones de dólares, obtenidos de "reservas de libres disponibilidad" (una categoría creada para este fin particular) del Banco Central.

${ }^{16}$ La deuda externa pasó de 62 mil millones dólares en los inicios de los noventa a 110 mil millones al finalizar la década. Junto con ese incremento el gobierno fue subordinando toda su política a las exigencias de los organismos estatales que actuaron como supervisores, lo cual significaba una cesión de las potestades estatales (Míguez, 2013).
} 
Centro Internacional de Arreglo de Diferencias Relativas a Inversiones (CIADI) y la colocación de deuda en mercados externos.

Sin embargo, Kulfas (2014) señala que el mecanismo de pago de deuda con reservas que se había utilizado en el canje 2005-2010, cuando el crédito para Argentina no era viable a tasas razonables, ya no era relevante pero que el gobierno lo había adoptado como bandera ideológica:

"Lo notable entonces fue que éste decidió cambiar de estrategia en su peor momento de fragilidad y vulnerabilidad, no por convicción sino por necesidad. Ello explica por qué, luego de años sin negociaciones fructíferas con el Club de París, el Ministro de Economía cerró un acuerdo en 24 horas en el cual accedió a pagar toda la deuda, con intereses vencidos y hasta el último punitorio" (Kulfas, 2014:15).

Como resultado se llegó a un acuerdo para pagar 9.700 millones de dólares de deuda de capital a cancelar en un período de 5 años. De este modo, a diferencia de la negociación del canje de 2005, catalogada como exitosa por sus condiciones sin precedentes a favor del deudor, los procesos "negociados" en 2014 parecieron más "un conjunto de concesiones de un país con escasas capacidades de maniobra en el Sistema Internacional por estar acorralado" (Bueno, 2015:12).

Pero más allá de las lecturas particulares sobre los procesos negociadores, fue claro que dichos actos de gobierno tuvieron la intención de demostrar que a pesar de sus debilidades el país podía defender sus posturas en defensa del crecimiento económico para dar sostenibilidad a la capacidad de pago en las negociaciones con los actores y organismos financieros internacionales.

\section{La relación con Estados Unidos y el No al ALCA}

Con el mismo espíritu de recuperar márgenes de maniobra, el kirchnerismo planteó una relación más distante con Estados Unidos. El abandono del alineamiento automático, más allá de un discurso por momentos confrontativo, no implicó la divergencia en temas centrales para el gobierno estadounidense, tales como la lucha contra el terrorismo y el narcotráfico. De este modo, no tuvo lugar un "cambio" en las relaciones con Estados Unidos sino más bien un "ajuste" $"$ (Busso, 2006).

Un tema que ejemplifica el ajuste es el cambio en la postura hacia Cuba, habiendo Argentina jugado un rol fundamental en la revitalización de los mecanismos políticos multilaterales latinoamericanos. La V Cumbre de la Organización de Estados Americanos (OEA) fue el marco propicio para dar inicio a la solución de la "cuestión cubana". Desde fines de 2008, el gobierno argentino desarrolló una estrategia conjunta con otros países latinoamericanos que incluyeron una serie de visitas presidenciales a la isla y la incorporación de Cuba al Grupo Río con el objetivo de que el gobierno cubano fuese reincorporado a la OEA y finalizara el bloqueo económico propiciado por Estados Unidos. Asimismo, cambió su voto condenatorio al régimen cubano por la abstención en el Conejo de Derechos Humanos de la ONU.

De acuerdo con Busso (2010), luego de las negociaciones para la salida de la cesación de pagos, no emergió un tema bilateral que haya sido lo suficientemente significativo para marcar el perfil de la relación y de allí en más hubo una baja densidad en los vínculos y una recomposición de los mismos a partir del gobierno de Cristina Kirchner ${ }^{18}$.

La llegada de Barack Obama a la Presidencia estadounidense no produjo cambios sustanciales en el vínculo bilateral, Argentina seguía estando fuera de las prioridades. Sin embargo, para sorpresa de muchos, se expresaron ciertas coincidencias sobre las visiones del mundo. En este marco, la cooperación bilateral continuó su cauce con el mismo nivel que en la

\footnotetext{
${ }^{17}$ De acuerdo con Russell (1990), un cambio de política exterior implica un realineamiento de un país con respecto a las principales coaliciones, fisuras globales o regionales y un ajuste señala alteraciones en el comportamiento de política exterior que no llevan a un realineamiento básico.

${ }^{18}$ En esta etapa, el Gobierno de Fernández de Kirchner brindó respuestas a los requerimientos de Washington y obtuvo el apoyo del gobierno ante los organismos de crédito internacionales.
} 
década del noventa. La retórica y los desencuentros presidenciales no afectaron los intereses mutuos y hubo una silenciosa coincidencia sobre la participación argentina en Haití, de interés para Washington en función de mantener bajo control la región (Russell, 2010).

En la misma línea, De la Balze (2010) plantea que a pesar de la retórica antiestadounidense, no hubo conflictos de fondo que empañaran la relación. La medida de mayor confrontación fue el "No" al ALCA, cuyo rechazo, sin embargo, no produjo mayores secuelas en el vínculo. Esto se debió a que las prioridades norteamericanas habían cambiado al rubro de la seguridad tras el 11-S y en materia comercial con América Latina, Washington se concentró en los tratados bilaterales con sus vecinos cercanos y Colombia, Chile, Perú y Panamá.

El "No" al $\mathrm{ALCA}^{19}$ fue un claro signo de la ruptura de las "relaciones carnales" y de la preferencia por la opción latinoamericana, que en ese momento tomaba cuerpo en la Comunidad Sudamericana de Naciones ${ }^{20}$. Además, la reciente salida del default le daba al gobierno argentino aires para distanciarse explícitamente del gobierno estadounidense.

En la IV Cumbre de las Américas en Mar del Plata en 2005, estaba en juego si Estados Unidos avanzaría con la fijación de los plazos de ejecución del ALCA, lo cual significaba continuar con los paquetes neoliberales de libre comercio y mayor apertura. La postura más moderada de los países del MERCOSUR y las oposiciones más exacerbadas de Cuba y Venezuela ante la definición de los mencionados plazos en los acuerdos finales de la Cumbre, fueron claves para que se diera por tierra con esta pretensión. En palabras del ex Canciller Taiana, el ALCA: "era un modelo que contemplaba el liderazgo hegemónico de Estados Unidos y la subordinación de nuestras economías. Nosotros preferimos construir un modelo de integración basado en nuestras propias fuerzas, entre iguales. Consideramos que eso nos iba a dar más autonomía e iba a ser mejor para la defensa del interés nacional” (Taiana, 2013).

\section{La carta suramericana}

La decisión estratégica argentina de profundizar los mecanismos de cooperación e integración sudamericanos se insertan en la línea de una política autonómica. La autonomía en el siglo XXI, tal como señalan Russell y Tokatlián (2002), debe ser ejercida desde la regionalización, la cooperación con otros actores y la participación en regímenes internacionales. En este sentido, los vínculos especiales con la región reemplazaron el alineamiento automático con Estados Unidos.

Frente a un ALCA malherido fue fortaleciéndose la creación de la Unión de Naciones Suramericanas (UNASUR), caracterizada por la concertación política y la multidimensionalidad de sus áreas de trabajo, donde Argentina participó activamente al momento de estabilizar situaciones conflictivas que marcaron la región.

En cuanto a las situaciones conflictivas regionales, basta repasar que las Presidentas Cristina Fernández y Michelle Bachelet le dieron un rol protagónico al convocar a una cumbre de emergencia en Santiago de Chile en septiembre de 2008 con motivo de la situación que se estaba gestando en Bolivia en contra de Presidente Evo Morales, tras la cruel masacre de campesinos. Asimismo, fue a través de la UNASUR que el gobierno de Fernández convocó a sus pares para tratar la situación de las bases militares estadounidenses en Colombia en 2008. En el caso de quiebres democráticos, como la destitución del Presidente Zelaya en Honduras en 2009 y del

\footnotetext{
${ }^{19}$ El Área de Libre Comercio de las Américas (ALCA) era un proyecto estadounidense de integración económica inicialmente pautada para el año 2005. Sus orígenes pueden remitirse a la propuesta de Iniciativa para la Américas lanzada por el Presidente George Bush en 1990, fue reimpulsado por Bill Clinton en la Cumbre de las Américas de Miami (1994) y volvió a tratarse durante la Cumbre de Québec (2001).

${ }^{20}$ En 2004 se firmó el acuerdo fundacional de la Comunidad Sudamericana de Naciones -conformada por Argentina, Brasil, Uruguay, Paraguay, Venezuela, Bolivia, Perú, Ecuador, Colombia, Chile, Guyana y Surinam- que se institucionalizó en mayo de 2008 en la UNASUR a través del tratado de Brasilia.
} 
Presidente Lugo en 2012, el gobierno argentino apoyó a la UNASUR y acompañó las medidas de repudio. Otra amenaza desestabilizadora contenida desde la UNASUR fue el intento de golpe de Estado por parte de las fuerzas de seguridad internas al Presidente Rafael Correa en 2010, cuando se sublevó el Regimiento de Policía Quito.

El MERCOSUR en tanto, se consolidó como eje prioritario de la política exterior kirchnerista tanto a nivel económico como político. El MERCOSUR funcionó como una herramienta para relacionarse con terceros actores, insertarse económicamente en el mundo y también como vía de aumento de autonomía (Zelicovich, 2011). El bloque fue un espacio donde tuvo lugar la articulación con Brasil, sobre todo en temas espinosos para la relación. Entre ellos figuran las disputas comerciales y los vínculos con Venezuela, cuyo ingreso consolidó el llamado eje Buenos Aires-Brasilia-Caracas.

Cuando se cumplían diez años de la firma del Tratado de Asunción, el bloque se encontraba sin posibilidades de alcanzar sus objetivos de integración ante medidas proteccionistas de sus miembros y tampoco avanzaba en la agenda externa. Pero tras este período, a partir del nuevo siglo, comenzaron a darse muestras de una voluntad pro-MERCOSUR en todos los países y el proceso integracionista comenzó una nueva etapa. Se recuperaron las economías nacionales, el comercio intra-bloque tomó un nuevo impulso y también se incrementó el comercio con socios extra-regionales, propiciado por una significativa mejora en los términos de intercambio externos para los bienes de origen primario producidos por los países del MERCOSUR. Aprovechando la dotación de recursos naturales, los Estados Parte aumentaron de manera destacable la producción y las exportaciones de productos alimenticios y materias primas hacia el resto del mundo. Comenzó de este modo a consolidarse un perfil exportador diferenciado, donde la región compra manufacturas de origen industrial y exporta al resto del mundo productos básicos (CEI, 2011).

Sin embargo, no hay que perder de vista que continuaron las dificultades en el bloque, tales como las escaladas bilaterales ante políticas proteccionistas, la extensión en el tiempo de una unión aduanera incompleta y la persistencia de las asimetrías entre las economías, sobre todo entre Uruguay y Paraguay por un lado y Brasil y Argentina por el otro, a pesar de iniciativas importantes como el Fondo de Convergencia Estructural del MERCOSUR (FOCEM) ${ }^{21}$.

El carácter intergubernamental del bloque hizo que sus avances y retrocesos estuvieran más en función de los compromisos políticos y la diplomacia presidencialista que en mecanismos institucionales. En este sentido, fue fundamental la perspectiva más política que se instaló para visualizar el proceso de integración en el marco del acercamiento programático e ideológico de los gobiernos de Argentina y Brasil. Se planteó entonces una nueva agenda de desarrollo donde se procuraba la consolidación democrática, el papel estratégico del Estado, el enfoque productivista, la integración social y una propuesta convergente en materia de política externa.

En 2012 se produjeron dos hitos que marcaron la relevancia de la dimensión política del bloque. En primer lugar la suspensión del gobierno de Paraguay en junio de 2012 en función de la cláusula democrática del bloque $\mathrm{e}^{22}$ tras el golpe institucional que quebró el orden democrático en el país y la salida anticipada de su Presidente, Fernando Lugo. En segundo lugar, la incorporación de Venezuela como miembro del bloque. Además de ser una señal de entendimiento político del eje Buenos Aires-Brasilia-Caracas, teniendo en cuenta la demora que sufrió la aprobación en el Senado brasileño, la incorporación venezolana fue un hecho

\footnotetext{
${ }^{21}$ El FOCEM está destinado a financiar proyectos en beneficio de las economías menores. Está operativo desde 2006, siendo el primer instrumento financiero del bloque con el objetivo de contribuir a la reducción de las asimetrías. Está integrado por contribuciones financieras de los Estados Partes para promover la convergencia estructural; desarrollar la competitividad; promover la cohesión social, en particular de las economías menores y regiones menos desarrolladas; y apoyar el funcionamiento de la estructura institucional, así como el fortalecimiento del proceso de integración.

${ }^{22}$ En función del Protocolo de Ushuaia I, firmado el 24 de julio de 1998 por los Estados Partes del MERCOSUR y los Estados asociados de Chile y Bolivia, que señala como condición esencial para los miembros la plena vigencia del orden democrático y prevé mecanismos ante la ruptura del mismo.
} 
geopolítico y geoeconómico, al contar el bloque desde ese momento con 270 millones de habitantes, un tercio del PBI regional y sumar importantes reservas de petróleo, siendo que la cuestión energética se encontraba en el tope de la agenda regional.

En cuanto a las relaciones bilaterales, se destacan en este trabajo las desarrolladas con Bolivia, Brasil, Chile y Venezuela en tanto dan cuenta de la importancia de la región para la política exterior kirchnerista. Dicha selección responde a que se han mantenido en un nivel profundo los vínculos que eran estratégicos en los años noventa, es decir Brasil y Chile, y se han densificado los lazos con Venezuela y Bolivia (Lorenzini, 2009). En estos últimos casos, la sintonía ideológica y los intereses argentinos en el gas natural boliviano y en el fuel-oil venezolano (esencial para el funcionamiento de las usinas eléctricas) fueron variables determinantes para aumentar la densidad de los vínculos.

Con Brasil se afianzaron los vínculos políticos durante las Presidencias kirchneristas. La firma del Acta de Copacabana ${ }^{23}$ en marzo de 2004 y el Compromiso de Puerto Iguazú de noviembre de $2005^{24}$, fueron muestra temprana de que se pretendía avanzar en la "asociación estratégica" que fuera asimismo el motor del proceso de integración regional.

La dinámica de la relación argentino-brasileña en su dimensión política-diplomática fue central para la resolución de los conflictos comerciales que periódicamente la ensombrecieron. En este aspecto, además de las diferencias bilaterales por cuestiones de intercambio comercial, tuvieron lugar algunos distanciamientos significativos en las posturas adoptadas en ámbitos multilaterales. Tal fue el caso de las posturas divergentes en la Ronda Doha de la Organización Mundial de Comercio (OMC) $)^{25}$.

Respecto a Chile, se continuó la relación estrecha que desde hace dos décadas muestra "una voluntad de fortalecimiento del vínculo donde sobresalen el interés pragmático de ambas partes por la resolución de cuestiones sensibles así como también por el establecimiento de mecanismos institucionales que faciliten el diálogo, fortalezcan los objetivos y se orienten, en una diversidad de temas de agenda, hacia lo que debe ser una relación «estratégica»" (Colacrai, 2010:358). La llamada "crisis del gas" de $2004^{26}$ fue un foco de tensión en el cual no fue posible que los gobiernos consensuaran la salida e impactó negativamente en la relación. No obstante, no se extendió a otras áreas temáticas de la agenda en función de que los Presidentes Kirchner y Lagos hicieron esfuerzos para des-gasificar la relación (Lorenzini, 2009).

En el caso de los vínculos con Venezuela, los acuerdos en materia energética y financiera $^{27}$ y el comercio superavitario creciente para la balanza externa argentina fueron ejes troncales en una relación de alta densidad. Mientras Venezuela ha contribuido en materia de energía y financiamiento con Argentina, ésta incrementa su cooperación en materia agroalimentaria. De acuerdo con Briceño Ruiz (2010), el pragmatismo y el interés mutuo signaron la relación más que las afinidades ideológicas. Las matrices políticas e ideológicas entre

\footnotetext{
${ }^{23}$ Suscripta entre los Presidentes Kirchner y Da Silva en Río de Janeiro el 16 de marzo de 2014. Abarca tres grandes áreas: colaboración diplomática, integración territorial y definiciones comunes sobre el sistema internacional.

${ }^{24}$ El Compromiso de Puerto Iguazú: Desarrollo, Justicia e Integración, fue firmado el 30 de noviembre. En el mismo se expusieron las intenciones de profundizar la integración regional, tener principios uniformes para insertarse en el sistema internacional, profundizar la alianza estratégica, integrar a la región energéticamente y reformular las pautas de negociación con los organismos financieros internacionales.

${ }^{25}$ En una etapa de la Ronda en julio de 2008 la Argentina y Brasil no coincidieron en materia de protección industrial. Hubo disensos sobre el nivel de aranceles para que los países en desarrollo protegieran los sectores considerados más sensibles. La propuesta inicial de la OMC era del 12\%, mientras Argentina defendía la protección del 16\% de sus ítems arancelarios y Brasil estaba dispuesto a proteger el 14\%, que acabó siendo la propuesta final de la OMC.

${ }^{26}$ La denominada crisis del gas surgió a fines de marzo de 2004 cuando el gobierno argentino decidió restringir la exportación de gas natural a la República de Chile a través de la Resolución 265/2004 y la Disposición 27/04 de la Secretaría de Energía de la Nación.

${ }^{27}$ Entre 2003-2007 Venezuela fue el principal proveedor de capitales externos de Argentina por medio de la compra de bonos de deuda pública nacional.
} 
ambos gobiernos están muy diferenciadas. Basta ver que el gobierno venezolano promueve un "socialismo del XXI" y critica al capitalismo, y el argentino un "capitalismo nacional".

Finalmente, se destaca la relación con Bolivia, la cual se profundizó tras el apoyo que le brindó el gobierno de Kirchner a la transición política boliviana que culminó con la asunción de Evo Morales en 2006, a quien los gobiernos kirchneristas apoyaron en las diferentes etapas de inestabilidad de su gobierno. Tras la nacionalización de los hidrocarburos, el gobierno argentino a través de los vínculos políticos mantuvo los acuerdos gasíferos e incentivó la realización de obras de infraestructura binacionales. De acuerdo con Tini (2008) es interesante observar cómo a partir de la transversalidad en la agenda bilateral que impuso la cuestión energética, se abordaron otros temas pendientes, como el de la comunidad boliviana en Argentina.

De esta manera, la integración regional definida durante los gobiernos kirchneristas como prioridad de la política exterior, da cuenta de que el desarrollo nacional está íntimamente vinculado al desarrollo de la región. En este sentido, la autonomía hace referencia a la ampliación de "capacidades potenciadas con otros", tal como plantea Colacrai (2009) al abordar las dimensiones de la autonomía regional.

\section{La vuelta al Sur}

Las relaciones con el Sur fueron desechadas en los años noventa y retomadas a partir de 2003. La vinculación con el Movimiento de No Alineados (NOAL) es un indicador claro de este cambio de postura hacia los países en desarrollo: en 1991 Argentina se retiró del Movimiento y en 2009 reingresó como observador luego de asistir como invitado a la Cumbre de La Habana de 2006.

Durante las administraciones kirchneristas las relaciones con el Sur extra-regional fueron revalorizadas en tanto presentaron espacios propicios para que el gobierno expresara a nivel internacional sus intereses nacionales tanto políticos como económico-comerciales. En lo que respecta a cuestiones político-diplomáticas, tal como ya sucediera en las década del setenta y el ochenta, en los países en desarrollo el gobierno encontró un alto respaldo a la cuestión de Malvinas, que nuevamente fue enarbolada como tema prioritario de la política exterior argentina. La expresa identificación del tema en los documentos de los foros como UNASUR, América del Sur-Países Árabes (ASPA), América del Sur-África (ASA), el G77+China y la CELAC, indican el interés del gobierno argentino por evidenciar el aval internacional al reclamo sobre la soberanía de las islas.

En la misma línea se inscribe la coordinación procurada con pares con el propósito de fijar posiciones en la agenda mundial, particularmente en referencia a los temas vinculados con la arquitectura financiera internacional, la reforma democrática del Consejo de Seguridad de Naciones Unidas y la promoción de políticas integrales de desarrollo y comercio. Como ejemplo puede tomarse la procuración de consensos con los países del Sur en instancias previas a las reuniones del G-20 28 , tales como la convocatoria realizada junto con Brasil en noviembre de 2011 para coordinar posturas entre los Ministros de Economía de la UNASUR antes de la Cumbre de Cannes, o la posición común adoptada junto al grupo BRICS en abril de 2012 para asistir a la Cumbre de Ministros de Comercio.

\footnotetext{
${ }^{28}$ El G20 es un foro informal que se originó en respuesta a las crisis financieras de las economías emergentes a finales de la década de 1990 pero que se jerarquizó en 2008 al generar una respuesta coordinada a la crisis financiera internacional de modo tal que diversos especialistas señalan que se encuentre en proceso de reemplazo del G8. El G20 refleja los cambios en el sistema internacional al reunir junto con los países desarrollados a los emergentes con el objetivo de promover la cooperación económica global. Sus miembros son: Alemania, Arabia Saudita, Argentina, Australia, Brasil, Canadá, China, Corea del Sur, Estados Unidos, Francia, Gran Bretaña, India, Indonesia, Italia, Japón, México, Rusia, Sudáfrica, Turquía, Unión Europea.
} 
Asimismo, en las reuniones de trabajo con los países del Sur, el gobierno defendió y buscó apoyo en posiciones sobre temas que considera que afectan la soberanía nacional. Junto con Malvinas, un caso emblemático ha sido la condena a los "fondos buitres" y la cuestión de la reestructuración de las deudas soberanas, temas de agenda presentes en las reuniones de alto nivel multilaterales y bilaterales con África y Asia. Además, en función de la experiencia argentina con los "fondos buitres", el gobierno impulsó desde el G77+China la adopción de una resolución en la Asamblea General de Naciones Unidas referida a la necesidad de establecer un marco legal multilateral para aumentar la eficiencia, estabilidad y previsibilidad del sistema financiero internacional. Como resultado, en septiembre de 2014 , en el marco del $69^{\circ}$ período de sesiones de la Asamblea General, se adoptó la resolución 68/304 "Hacia el establecimiento de un marco jurídico multilateral para los procesos de reestructuración de la deuda soberana" por 124 votos a favor, 11 en contra y 41 abstenciones $^{29}$.

En lo que respecta a la promoción del comercio Sur-Sur, cabe señalar el contexto propicio para los intercambios entre países en desarrollo. En la última década el comercio SurSur ha tenido un protagonismo central en el cambio de la estructura comercial mundial. En el caso argentino, entre 2003 y 2011, las exportaciones experimentaron un proceso de diversificación de destinos ubicados en el Sur. El único destino tradicional que incrementó su participación desde el año 2002 fue el MERCOSUR. China se ubicó como segundo destino de las exportaciones y se observaron retrocesos en las exportaciones al NAFTA y a la Unión Europea, que redujeron su participación en $6 \%$ y $4 \%$ respectivamente (Calore, 2013). No obstante, los últimos años del gobierno de Cristina Fernández de Kirchner se desarrollaron en un contexto signado por el estancamiento comercial internacional ${ }^{30}$ y una retracción del comercio exterior argentino, con el consecuente impacto sobre el intercambio comercial entre Argentina y el Sur ${ }^{31}$.

La lectura del gobierno argentino fue que el sostenimiento del crecimiento económico mundial en la primera década del siglo se debió a la dinámica económica de los países de la periferia ante la crisis desatada en Europa y Estados Unidos. En efecto, el comercio se erigió como un pilar central en el armado Sur-Sur argentino y el incremento de su incidencia en su balanza comercial es un aliciente para la profundización de los vínculos con los países en desarrollo. Tal como indica Vagni (2008) los gobiernos kirchneristas acentuaron el enfoque comercialista implementado en los noventa, pero bajo el discurso de la cooperación Sur-Sur ${ }^{32}$.

En este marco, se extendieron los vínculos con los Estados del Sur extra-regional, tal como puede observarse en el caso de África Subsahariana, interesante de analizar dada su exclusión de la agenda externa durante los gobiernos menemistas ${ }^{33}$. Así, bajo el paraguas discursivo de la cooperación Sur-Sur se extendieron los vínculos político-diplomáticos, el comercio y la cooperación técnica.

\footnotetext{
${ }^{29}$ El documento aboga por la intensificación de los esfuerzos por prevenir las crisis de deuda mejorando los mecanismos financieros internacionales de prevención y solución de crisis, en cooperación con el sector privado. Posteriormente, en el mes de diciembre, la Asamblea General aprobó la conformación del Comité Especial de Naciones Unidas sobre los Procesos de Reestructuración de la Deuda Soberana, el cual comenzó a sesionar en febrero de 2015.

30 "El crecimiento del volumen del comercio ha sido muy lento en los últimos años, cifrándose en un 2,8\% en 2014 y en un 2,4\% de promedio en los últimos tres años (...) Varios factores contribuyeron a la desaceleración del comercio y la producción en 2014 y a principios de 2015, entre ellos un crecimiento más lento del PIB en las economías emergentes, la desigual recuperación en los países desarrollados y las crecientes tensiones geopolíticas" (UNCTAD, 2015).

${ }^{31}$ Tanto las importaciones como las exportaciones argentinas disminuyeron en un promedio de $15.5 \%$ (INDEC, 2015).

${ }^{32}$ La cooperación Sur-Sur alude a las acciones conjuntas entre los países periféricos para profundizar sus relaciones en pos de afrontar problemas comunes, defender intereses compartidos y obtener mayores márgenes de autonomía decisional. Es una construcción eminentemente política donde hay espacio para la estructuración de alianzas entre países en desarrollo que procuran disminuir sus vulnerabilidades e influir en el establecimiento de las reglas del sistema internacional (Lechini, 2009).

${ }^{33}$ Para un amplio análisis del período ver Lechini (2011).
} 
En lo que respecta a las relaciones institucionales, cabe señalar que se abrieron cuatro representaciones diplomáticas ${ }^{34}$ y se firmaron numerosos acuerdos que revelan el acercamiento: en el período 2003-2015 se suscribieron 67 (sesenta y siete) acuerdos, que representan casi el $46 \%$ de la totalidad de los acuerdos firmados con África Subsahariana en toda la historia ${ }^{35}$. En cuanto a visitas de alto nivel, se destaca la de la Presidenta a Angola en 2012 y los más de una docena de viajes de Cancilleres y Vicecancilleres a Sudáfrica, Kenia, Angola, Etiopía, Senegal, Costa de Marfil, Djibouti, Tanzania, República Democrática del Congo y Guinea Ecuatorial, principalmente a partir de $2007^{36}$.

La intención de acercamiento político también se expresó en la participación argentina en los procesos de inter-regionalismo inaugurados en los albores del siglo XXI. En las Cumbres ASPA y $\mathrm{ASA}^{37}$, Argentina reiteró la importancia de la cooperación Sur-Sur y el multilateralismo como mecanismos efectivos para alcanzar consensos con la meta de promover el desarrollo en ambas regiones y reformas en los organismos internacionales ${ }^{38}$.

La balanza comercial con África Subsahariana ha sido históricamente favorable para Argentina, profundizándose esta tendencia durante las administraciones kirchneristas. Nótese que entre 2003 y 2012, de un total exportado de 633 mil millones de dólares se pasó a 2.314 millones, en tanto las importaciones sólo aumentaron de 122 millones a 654 millones, si bien en un contexto mundial recesivo, en 2014 las exportaciones descendieron por debajo de los dos mil millones. Si bien la incidencia en el total de lo exportado a nivel mundial no alcanza la décima parte, esto no implica que no sea relevante, ya que el saldo casi completamente positivo es un insumo importante para equilibrar la balanza con los grandes socios, como China y Brasil ${ }^{39}$.

Asimismo, es importante indicar que junto a las actividades diplomáticas y el comercio se han desenvuelto acciones de cooperación técnica horizontal en sectores productivos e institucionales, sobresaliendo los proyectos de cooperación agrícola ${ }^{40}$. A modo de ejemplo puede considerarse el año 2014, donde desde el FO.AR se ejecutaron 29 (veintinueve) proyectos con África de un total de 248 (doscientos cuarenta y ocho). Si bien este número es relativamente

\footnotetext{
${ }^{34}$ Se abrieron Embajadas en Angola (2005), Etiopía (2012) y Mozambique (2013) y el Consulado de Johannesburgo (2010); además el país ingresó en calidad de observador de la Unión Africana (UA) en 2009 y de la Comunidad Económica de Estados de África Occidental (ECOWAS) en 2010. Este accionar se contrapone al cierre de las representaciones en la década previa: Costa de Marfil, Etiopía y Tanzania (1991), Zaire (1992) y Gabón (1993).

${ }^{35}$ Hasta el 2002 se suscribieron doscientos ochenta y ocho acuerdos. Como "acuerdos" se comprenden la totalidad de los documentos firmados bilateralmente, incluidos memorándum de entendimiento, actas, convenios y cartas de intención, que expresan una convergencia de deseo entre las partes y son más informales que un acuerdo, así como también acuerdos entre organismos gubernamentales. Fuente: elaboración propia en base a datos provistos en el sitio web de la Biblioteca de Tratados del MRECIC: tratados.cancilleria.gob.ar

${ }^{36}$ En el período 1989-2002 los Cancilleres y vice Ministros argentinos viajaron solamente a Sudáfrica, en el contexto del fin del apartheid.

${ }^{37}$ La primera Cumbre ASPA tuvo lugar en Brasilia (Brasil) en 2005, la segunda en Doha (Qatar) en 2009 y la tercera en Lima (Perú) en octubre de 2012. La primera Cumbre ASA se realizó en Abuja (Nigeria) en 2006, la segunda en Margarita (Venezuela) en 2009 y la tercera en Malabo (Guinea Ecuatorial) en febrero de 2013.

${ }^{38}$ Los vínculos generados en el marco de ASA y ASPA responden a una modalidad de relacionamiento entre regiones (inter-regionalismo) donde se establecen plataformas de concertación en las que los Estados participan a título individual, aunque existe algún tipo de coordinación intra-grupo, y las instituciones regionales también participan. Están basadas en reuniones más o menos regulares de alto nivel y en programas de cooperación, incluyendo iniciativas bilaterales y regionales. La definición de los grupos es más laxa, y pueden no coincidir con regiones formalmente constituidas (Sanahuja y Pacheco, 2008).

${ }^{39}$ Fuente de los datos comerciales: elaboración propia en base a información suministrada por el Instituto Nacional de Estadísticas y Censos en la publicación "Indec Informa”, varios números.

${ }^{40}$ Casos emblemáticos son el apoyo del Instituto Nacional de Tecnología Agropecuaria (INTA) a la autoproducción de alimentos frescos en Mozambique, que comenzó en 2012, y a la implementación de campos experimentales para la aplicación de la siembra directa en Sudáfrica a partir de 2009 (Morasso, 2015).
} 
pequeño, la relevancia de los mismos se basa en el aumento de las iniciativas, lo cual es observable si se compara con los proyectos ejecutados en 2012, que fueron 6 (seis). Esto implicó que del total de expertos argentinos enviados al exterior, 63 (sesenta y tres) se dirigieran a los países africanos y que se realizaran 29 (veintinueve) misiones (MRECIC, 2015).

Como resultado, una región que había sido olvidada por la política exterior neoliberal, se reincorporó en la agenda externa, aunque manteniendo un espacio periférico. Tal es así que Argentina fue calificada por la Comisión Económica para África de Naciones Unidas como un emerging partner (Afican Development Bank et. al., 2011) en tanto fue considerada como una economía emergente cuyas relaciones económicas con África crecieron rápidamente ${ }^{41}$, brindando a los socios africanos asistencia técnica diseñada en el Sur y proveyendo bienes de consumo accesibles a sus nuevas clases medias y bienes de capital adaptados a las singularidades productivas.

\section{Conclusiones}

La política exterior argentina durante las administraciones de Néstor Kirchner y Cristina Fernández de Kirchner puede ser caracterizada por su orientación autonomista, la cual respondió a los intereses políticos y económicos domésticos.

El abandono de la política de alineamiento automático con Estados Unidos y la búsqueda de un modelo de crecimiento económico heterodoxo distanciado de las recetas de los organismos internacionales de crédito, que se plasmó en el pago de la deuda con el FMI y la salida del default, fueron representaciones claras de la ruptura con la política exterior de la década del noventa. No obstante, la autonomía practicada no implicó la oposición total a las acciones de la potencia hegemónica. De hecho, continuaron las políticas de cooperación y hubo coincidencias en temas centrales para Estados Unidos. Así, los rasgos autonómicos estuvieron presentes principalmente en la defensa de lo que para las administraciones kirchneristas eran los intereses nacionales y en la toma de decisiones independiente de lo que consideraban una injerencia negativa de actores externos, aunque con articulación con el medio internacional.

Por otra parte, atendiendo a que en el contexto actual la autonomía decisoria de un país no puede comprenderse desde el aislamiento, sino que por el contrario, debe incluir estrategias de internacionalización, la concertación política con actores de la región formó parte del modelo de orientación autonomista. La solidaridad regional se constituyó en una meta política que expresó los intereses nacionales. La agenda política de la integración y la reafirmación de la soberanía suramericana permitieron a estos gobiernos tomar posiciones sobre cuestiones globales y de interés nacional con el respaldo regional.

Por último, cabe subrayar que se profundizó la cooperación Sur-Sur como una línea de acción. Se promovió el diálogo con los países en desarrollo con el propósito de ampliar el consenso en torno a temas de gobernanza global y para incrementar los apoyos a la postura argentina en el reclamo sobre las Islas Malvinas y en temas de particular interés, como la reforma del sistema financiero internacional. No obstante, la generación de alianzas intercontinentales, como las impulsadas por Brasil (BRICS, IBSA), no fue un objetivo de la política exterior argentina.

La faceta comercial, comprendida como las acciones político-diplomáticas impulsadas por los actores gubernamentales en materia económico-comercial, tuvo un rol fundamental en la ampliación de los vínculos con el Sur. La intención fue diversificar el mapa de los socios comerciales para sostener una balanza externa positiva e incrementar la exportación de bienes con valor agregado. En paralelo, los proyectos de cooperación técnica fueron instrumentos a través de las cuales el gobierno argentino procuró fortalecer vínculos con terceros países desde la concepción de la horizontalidad y la solidaridad, convirtiéndose en herramientas eficaces para

${ }^{41}$ Dentro de este grupo, se ha identificado a Argentina junto a los BRIC, Turquía, Tailandia, Corea, Singapur, Malasia, Indonesia, Arabia Saudita y los Emiratos Árabes. 
lograr procesos de acercamiento con aquellos países que por distancias geográficas, culturales y políticas estuvieron desconectados de la realidad argentina.

De este modo, a través de las negociaciones financieras internacionales, de las relaciones con Estados Unidos y con la región y de la cooperación Sur-Sur ha sido posible observar la orientación autonomista que guió en el plano internacional a las administraciones kirchneristas.

\section{Referencias Bibliográficas}

AFRICAN DEVELOPMENT BANK, ORGANISATION FOR ECONOMIC CO-OPERATION AND DEVELOPMENT, UNITED NATIONS DEVELOPMENT PROGRAMME, UNITED NATIONS ECONOMIC COMMISSION FOR AFRICA (2011). African Economic Outlook 2011: Africa and Its Emerging Partners, OECD Publishing

ARANÍBAR, A.; RODRIGUEZ, B. (2013). Latinoamérica, ¿del neoliberalismo al neodesarrollismo?, en ARANÍBAR, A.; RODRÍGUEZ, B. (coord.). América Latina, ¿del neoliberalismo al neodesarrollismo?, Siglo Veintiuno Editores, Buenos Aires

BANCO MUNDIAL (2016). Indicadores de Desarrollo Mundial. Disponible en: http://databank.bancomundial.org/data/reports. aspx? source $=2 \&$ country $=A R G \&$ series $=\&$ period $=$. Consulta: 5 de febrero de 2016

BOLOGNA, A. B. (2008). La vigencia de la Teoría de la Autonomía de Puig para analizar el Gobierno de Menem, en Revista Ágora Internacional, Año 3, $\mathrm{N}^{\circ}$ 6, Asociación para las Naciones Unidas de la República Argentina, Buenos Aires

BOLOGNA, A. B. (2010). La autonomía heterodoxa de la Política Exterior de Néstor Kirchner, en VARIOS AUTORES, La política exterior de Cristina Fernández. Apreciaciones promediando su mandato, Tomo V, CERIR, Rosario

BRICEÑO RUIZ, J. (2010). Venezuela y Argentina en la era Chávez y Kirchner: ¿Coincidencia ideológica o pragmatismo?, en VARIOS AUTORES, La política exterior de Cristina Fernández. Apreciaciones promediando su mandato, Tomo V, CERIR, Rosario

BRICEÑO RUIZ, J.; SIMONOFF, A. (eds.) (2014). Integración y cooperación regional en América Latina. Una relectura a partir de la teoría de la Autonomía, Editorial Biblos, Buenos Aires

BUENO, M.P. (2015). Política Exterior Argentina. Reacción, sobreactuación e irrelevancia. La frustración de la autonomía, ponencia presentada en la Conferencia FLACSO-ISA 2014, Buenos Aires. Disponible en: http://web.isanet.org/Web/Conferences/FLACSOISA\%20BuenosAires\%202014/Archive/71f2ca0d-f601-483d-9dab-d6d578179bd3.pdf. Consulta: 5 de febrero de 2016

BUSSO, A. (2006). La presidencia de Kirchner y los vínculos con Estados Unidos. Más ajustes que rupturas, en VARIOS AUTORES, La política exterior del gobierno de Kirchner, Tomo IV, CERIR, Rosario

BUSSO, A. (2010). Política Exterior y Relaciones bilaterales con Estados Unidos durante el gobierno de Cristina: tensiones entre los objetivos de la campaña electoral y el renacer de los condicionantes internos, en VARIOS AUTORES, La política exterior de Cristina Fernández. Apreciaciones promediando su mandato, Tomo V, CERIR, Rosario

CALORE, M.C. (2013). El nuevo patrón de inserción internacional: diversificación, industrialización y superávit, en Contexto Internacional, 36, FUNIF, Rosario

CARriLlo, C. (2016). Pagó Argentina y la alegría no es sólo de Singer, en Página 12, 23 de abril, Buenos Aires

CARUGATI, M. (2015). Argentina, un país proteccionista, en El Economista Diario, Buenos Aires. Disponible en: http://www.eleconomista.com.ar/2015-01-argentina-un-pais-proteccionista-2/. Consulta: 5 de febrero de 2016 
CENTRO DE ECONOMÍA INTERNACIONAL (CEI) (2011). MERCOSUR: a 20 años del Tratado de Asunción, Notas del CEI, 20, Ministerio de Relaciones Exteriores, Comercio Internacional y Culto, Buenos Aires, abril

COLACRAI, M. (2009). Los aportes de la teoría de la autonomía, genuina contribución sudamericana ¿La autonomía es hoy una categoría en desuso o se enfrenta al desafío de una renovación en un contexto interdependiente y más complejo?, en LECHINI, G.; KLAGSBRUNN, V.; GONÇALVES, W. (comp.). Venciendo preconceptos: Las variadas aristas de una concepción estratégica, Revan, Rio de Janerio

COLACRAI, M. (2010). Argentina-Chile. Las relaciones políticas y el crecimiento de un notable tejido de vínculos a escala nacional y subnacional, en VARIOS AUTORES. La política exterior de Cristina Fernández. Apreciaciones promediando su mandato, Tomo V, CERIR, Rosario

CONFERENCIA DE NACIONES UNIDAS SOBRE COMERCIO Y DESARROLLO (UNCTAD) (2015). Proseguirá la modesta recuperación del comercio en 2015 y 2016 después de tres años de débil expansión, Press/739, 14 de abril, Ginebra

CONSEJO NACIONAL DE COORDINACIÓN DE POLÍTICAS SOCIALES PRESIDENCIA DE LA NACIÓN y PROGRAMA DE NACIONES UNIDAS PARA EL DESARROLLO (PNUD) (2012), Objetivos de Desarrollo del Milenio. Informe País Argentina 2010, Buenos Aires

CORIGLIANO, F. (2008). Híbridos teóricos y su impacto en la política exterior: El caso de los gobiernos de Néstor y Cristina Kirchner, en Boletín ISIAE, 47, CARI, Buenos Aires.

DE LA BALZE, F. (2010). La política exterior de los gobiernos Kirchner (2003-2009), en Estudios Internacionales, $\mathrm{N}^{\circ}$ 166, Universidad de Chile, Santiago de Chile

DIRECCION GENERAL DE COOPERACIÓN INTERNACIONAL (2015). Balance de Gestión 2014, Ministerio de Relaciones Exteriores y Culto de Argentina, Buenos Aires

ESCUDÉ, C. (1995). El realismo de los estados débiles, GEL, Buenos Aires

FONDO DE LAS NACIONES UNIDAS PARA LA INFANCIA y COMISIÓN ECONÓMICA PARA AMÉRICA LATINA (UNICEF; CEPAL) (2006), Efectos de la crisis en Argentina. Las políticas del Estado y sus consecuencias para la infancia, Buenos Aires

JUEGUEN, F. (2015), Por un fallo de la OMC, el Gobierno eliminará trabas al comercio exterior, en Diario La Nación, 14 de julio, Buenos Aires

GROTTOLA, L. (2010). Neo-desarrollismo y rol del Estado (Argentina 2003-2010), presentación en el V Congreso Latinoamericano de Ciencia Política, organizado por la Asociación Latinoamericana de Ciencia Política (ALACIP), Buenos Aires

INSTITUTO NACIONAL DE ESTADÍSTICAS Y CENSOS (INDEC) (2015). Argentine Foreign Trade Statistics, Ministerio de Economía y Finanzas, mayo, 19(1), Buenos Aires

KIRCHNER, N. (2003). Discurso de Asunción del Presidente, pronunciado ante el Congreso Nacional, 25 de mayo, Buenos Aires

KIRCHNER, N. (2007). Discurso en el anuncio de obras para la Patagonia, 16 de mayo, Santa Cruz

KULFAS, M. (2014). La economía argentina, entre la «década ganada» y los «fondos buitre»", en Nueva Sociedad, 254, noviembre-diciembre, Buenos Aires

GOMEZ SARAIVA, M. (2011). Brazilian Foreign Policy: casual beliefs in formulation and pragmatism in practice, en GIARDINI, G. y LAMBERT, P. (ed.). Latin American Foreign Policies: Between Ideology and Pragmatism, Palgrave Macmillan, Nueva York

GRATIUS, S.; GOMES SARAIVA, M. (2013). Continental Regionalism: Brazil's prominent role in the Americas, CEPS Working Document, 374, febrero, Bruselas

LECHINI, G. (2009). La cooperación Sur-Sur y la búsqueda de autonomía en América Latina ¿Mito o realidad?, en Relaciones Internacionales, 11, Universidad Autónoma de Madrid, Madrid

LECHINI, G. (2011). Argentina and South Africa facing the challenges of the XXI Century: Brazil as the mirror image, UNR, Rosario

LORENZINI, M.E. (2009). La relación bilateral argentino-chilena 1999-2007 ¿Alianza estratégica o profundización del vínculo bilateral? Análisis desde el enfoque de las macro y micro-relaciones, Tesis doctoral, Doctorado en Relaciones Internacionales, Universidad Nacional de Rosario, Rosario 
LORENZINI, M.E. (2012). Las estrategias de inserción internacional de Argentina, Chile y Venezuela: Primera aproximación a un análisis comparado, ponencia presentada en el X Congreso Nacional y III Congreso Internacional sobre Democracia, Facultad de Ciencia Política y Relaciones Internacionales de la UNR, septiembre, Rosario

LORENZINI, M.E.; PEREYRA DOVAL, G. (2013). Revisitando los aportes de las teorías del sur: nexos entre teoría y praxis en Argentina y Brasil, en Revista Relaciones Internacionales, 22, febrero-mayo, GERI - UAM, Madrid

MIGUEZ, M.C. (2013). Los partidos políticos y la política exterior argentina, Ariel, Buenos Aires

MIRANDA, R. (2005). Sobre los fundamentos internacionales de la política argentina: teoría y realidad, en Invenio, 8(105), UCEL, Rosario

MIRANDA, R. (2013). Anacronismo y actualidad autonomista: El problema del poder internacional de Argentina, en Relaciones Internacionales, 45, La Plata

MORASSO, C. (2015). La cooperación Sur-Sur argentina con África Subsahariana en materia agrícola (2003-2012), tesis de Doctorado en Relaciones Internacionales, Universidad Nacional de Rosario (UNR), Rosario

PIGNATTA, M.E. (2010). Identidad y política exterior. Explorando el caso argentino, en BUSSO, A, (comp.). Fuerzas profundas e identidad. Reflexiones sobre su impacto en la política exterior: un recorrido de casos, UNR Editora, EBook, v. 2, Rosario

PUIG, J.C. (1984). Introducción, en PUIG, J.C. (comp.). América Latina: Políticas Exteriores Comparadas, Tomo I, GEL, Buenos Aires

PEREYRA DOVAL, G. (2014). Autonomía en la Política Exterior de Lula da Silva, en LECHINI, G. (comp.). La cooperación sur-sur en las políticas exteriores de Argentina y Brasil en el siglo XXI', UNR Editora, Rosario

ROMERO, P. (2009). Hacia una nueva construcción discursiva de la autonomía, en LECHINI, G.; KLAGSBRUNN, V.; GONÇALVES, W. (comp.). Venciendo preconceptos: Las variadas aristas de una concepción estratégica, Revan, Rio de Janerio

RUSSELL, R. (1990). Política Exterior y Toma de Decisiones en América Latina, Programa RIAL, GEL, Buenos Aires

RUSSELL, R. (2010). La Argentina del segundo bicentenario: continuidades y ficciones de la política exterior, en RUSSELL, R. (ed.). Argentina 1910-2010. Balance de siglo, Taurus, Buenos Aires

RUSSEll, R.; TOKATLIÁN, J.G. (2001). De la Autonomía Antagónica a la Autonomía Relacional: una mirada teórica desde el Cono Sur, en Posdata Revista de Reflexión y Análisis Político, 7, Buenos Aires

RUSSELL, R.; TOKATLIÁN, J.G. (2002). De la autonomía antagónica a la autonomía relacional: una mirada teórica desde el Cono Sur, en Perfiles Latinoamericanos, 21

RUSSELL, R.; TOKATLIÁN, J.G. (2013). América Latina y su gran estrategia: entre la aquiescencia y la autonomía, en Revista Cidob d'Afers Internacionals, 104, Barcelona

SANAHUJA, J.; PACHECO, J. (2008). Dinámicas de la Sociedad Internacional (I): Integración y Regionalismo, Máster Interuniversitario en Diplomacia y Relaciones Internacionales, Escuela Diplomática, Ministerio de Asuntos Exteriores y Cooperación, Madrid

SIMONOFF, A. (2008). La política exterior de los Gobiernos Kirchnerista y la Tercera Posición, en Intellector, año IV, volumen V, julio-diciembre, Río de Janeiro

SIMONOFF, A. (2013). Democracia, política exterior y autonomía, en Cuestiones de Sociología, 9, Universidad Nacional de La Plata, La Plata

SIMONOFF, A. (2010). La Argentina y el mundo frente al bicentenario de la Revolución de Mayo: las relaciones exteriores argentinas desde la secesión de España hasta la actualidad, Universidad Nacional de La Plata, La Plata

TINI, M.N. (2008). La distancia sobre la cercanía: la política exterior de Argentina hacia Bolivia y Paraguay, en Relaciones Internacionales, 197, La Plata

VAGNI, J.J. (2008). Argentina-Marruecos. De los impulsos a la convergencia político-comercial (19892007), tesis doctoral, Doctorado en Relaciones Internacionales, Universidad Nacional de Rosario, Rosario 
VAN KLAVEREN, A. (1992). "Entendiendo las políticas exteriores latinoamericanas: modelo para armar", en Estudios Internacionales, año XXV, 98, Abril-Junio

TAIANA, J. (2013). A ocho años del No al ALCA, en Diario Página 12, 6 de noviembre, Buenos Aires

VIGEVANI, T.; RAMANZINI JÚNIOR, H. (2014). Autonomia, Integração Regional e Política Externa Brasileira: Mercosul e Unasul, en Dados Revista de Ciências Sociais, Universidade do Estado do Rio de Janeiro, 57 (2), abril-junio, Rio de Janeiro

VIGEVANI, T.; CEPALUNI, G. (2007). A política externa de Lula da Silva: a estratégia da autonomia pela diversificação, en Contexto Internacional, 29(2), Brasil

ZAKARIA, F. (2008). O mundo pós-americano, Companhiadas Letras, Sao Pablo

ZELICOVICH, J. (2011). El lugar del MERCOSUR en la política exterior argentina durante los gobiernos de Néstor Kirchner y Cristina Fernández de Kirchner, en Relaciones Internacionales, 41, Buenos Aires 